Proceeding

Open Access

D CrossMark

\title{
Cavernous sinus thrombosis case report
}

\section{Case scenario}

a. A Sudanese male 45years old medically has a history of poor controlled diabetes mellitus complaining from pain full swelling in the left side of the face after 48 hours spread to the other side.

b. Patient had shooting vital signs (pyrexia, tachypnea and tachycardia).

c. Extra-oral examination, proposis, dilated fixed pupils, ptosis, papill oedema, pus discharge and paralysis of extra ocular muscles.

d. Intra-oral examination, a firm swelling with badly carious left upper canine (Figures 1-4).

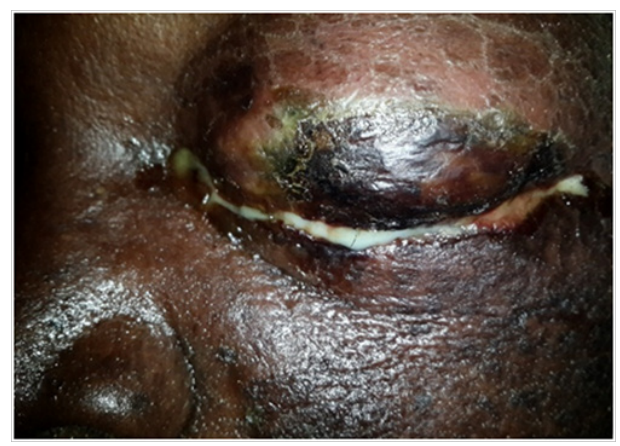

Figure I Shows pus discharge and proptosis in the left eye.

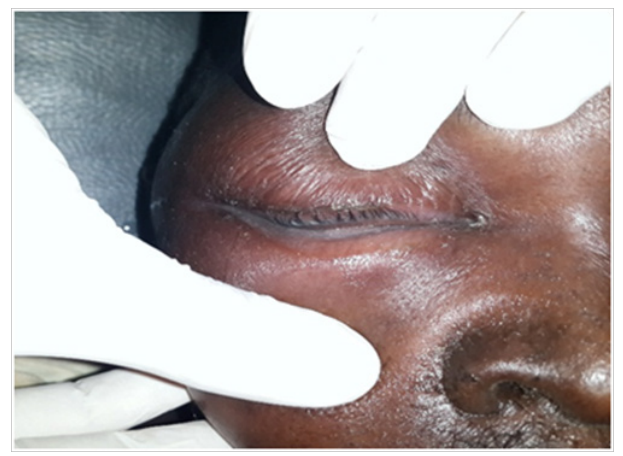

Figure $\mathbf{2}$ Shows complete ptosis of the right eye after $\mathbf{7 2 h o u r s . ~}$

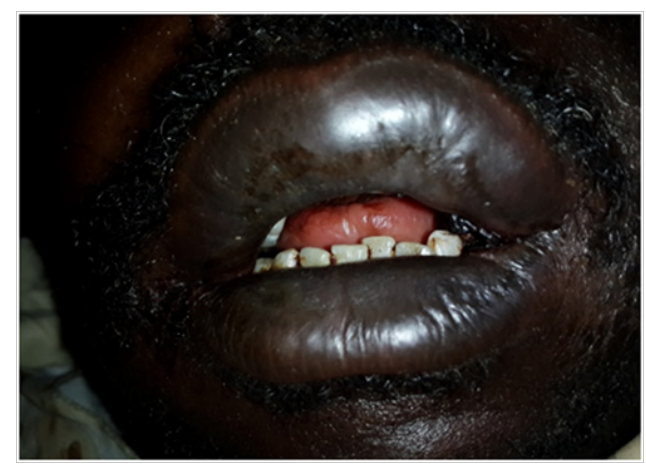

Volume 3 Issue I - 2016

Yousif I Eltohami,Amal H Abuaffan

Faculty of Dentistry, University of Khartoum, Sudan

Correspondence: Amal H Abuaffan, Faculty of dentistry, University of Khartoum, Sudan, Email amalabuaffan@yahoo.com

Received: April 26, 2016 | Published: September 16, 2016

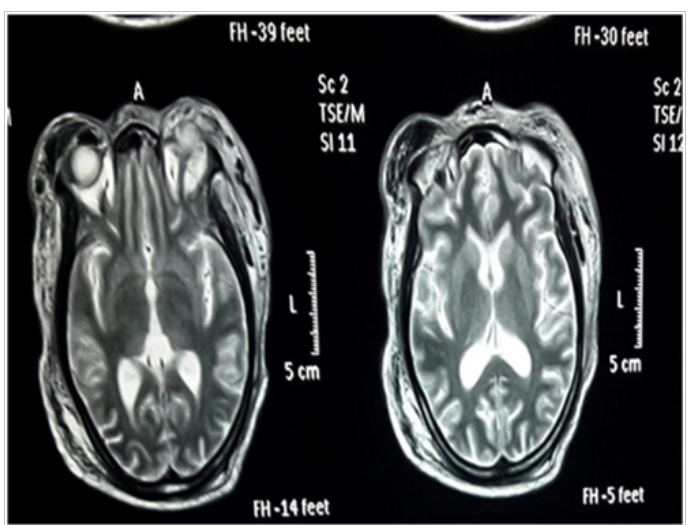

Figure 4 Shows T2 weighed MRI Showed bilateral involvement of the eyes.

\section{Acknowledgements}

None.

\section{Conflict of interest}

Author declares that there is no conflict of interest.

Figure 3 Shows swollen upper lip. 